\title{
Rancang Bangun Perangkat Pengukuran Debit Dan Suhu Air Berbasis Mikrokontroler ATMega 8535
}

\author{
Lili Solihin ${ }^{1}$ \\ Prodi Teknik Elektro FT UNPAM \\ JIn. Puspiptek Raya No 46 Buaran, Tangerang Selatan 15310 INDONESIA \\ 'dosen00860@unpam.ac.id
}

\begin{abstract}
ABSTRAK
Berkembangnya teknologi memungkinkan pembuatan alat ukur yang semula masih tradisional dan manual dalam penggunaannya menjadi lebih modern dan otomatis. Hal ini dapat dilihat pada terciptanya alat ukur yang semula masih menggunakan konsep manual sekarang menggunakan konsep digital. Alat -alat ukur tersebut antara lain timbangan digital, speedometer digital, thermometer digital, dll. Penerapan teknologi digital tersebut pun dapat dilakukan pada pengukuran debit dan suhu air yang masih menggunakan konsep manual dan belum terintegrasi dalam sebuah sistem. Perancangan sistem tersebut meliputi penggunaan Mikroprosesor ATMega 8535 untuk pengolahan data pengukuran, sensor aliran untuk mengukur laju aliran, sensor suhu untuk mengukur suhu, dan LCD $16 \times 2$ sebagai display hasil dari pengukuran yang telah dilakukan. Pada LCD akan ditampilkan data berupa debit dan suhu air.

Kata kunci : Pengukuran, Mikroprosesor ATMega 8535, sensor aliran, Flowmeter, sensor suhu LM 35, LCD $16 \times 2$, debit, volume, dan suhu.
\end{abstract}

\begin{abstract}
The development of technology allows the manufacture of traditional and still traditional measuring instruments in their use to be more modern and automatic. This can be seen in the creation of measuring instruments that are still using the manual concept now using the digital concept. The tools include digital scales, digital speedometer, digital thermometer, etc. The application of digital technology can also be done on the measurement of water discharge and temperature that still use manual concepts and not yet integrated in a system. The design of the system includes the use of ATMEGA 8535 Microprocessor for measurement data processing, flow sensor to measure flow rate, temperature sensor for temperature measuring, and $16 \times 2 L C D$ as display of result of measurement has been done. On the LCD will display data in the form of discharge and water temperature.
\end{abstract}

Keywords: Measurement, ATMega 8535 Microprocessor, flow sensor, Flowmeter, LM 35 temperature sensor, $16 \times 2$ LCD, discharge, volume, and temperature.Keywords: Solar energi, battery, Battery Control Unit 


\section{PENDAHULUAN}

Teknologi yang semakin canggih memudahkan manusia dalam melakukan berbagai macam kegiatan. Salah satunya yaitu kegiatan pengukuran terhadap besaran fisika antara lain suhu, volume, dan debit. Pengukuran yang sebelumnya dilakukan secara manual kini dapat dilakukan secara digital dan terintegrasi dalam sebuah sistem. Sehingga hasil pengukuran dapat dilihat dengan mudah dan tentunya lebih akurat.

Hal ini dapat kita lihat pada terciptanya alat ukur yang semula masih menggunakan konsep manual sekarang menggunakan konsep digital. Alat -alat ukur tersebut antara lain timbangan digital, speedometer digital, thermometer digital, dll. Penerapan teknologi digital tersebut pun dapat dilakukan pada pengukuran debit, volume, dan suhu air yang masih menggunakan konsep manual dan belum terintegrasi dalam sebuah sistem.

Berdasarkan hal tersebut, maka dirancanglah sebuah sistem pengukuran debit dan suhu air berbasis mikrokontroler ATMEGA 8535 yang terintegrasi. Perancangan sistem tersebut meliputi penggunaan Mikroprosesor ATMEGA 8535 untuk pengolahan data pengukuran, sensor aliran untuk mengukur laju aliran, sensor suhu untuk mengukur suhu, dan LCD sebagai display hasil dari pengukuran yang telah dilakukan.

\section{METODOLOGI}

Blok diagram, alat, perancangan, dan diagram kerja penelitian ini sebagai berikut :

\section{BLOK DIAGRAM}

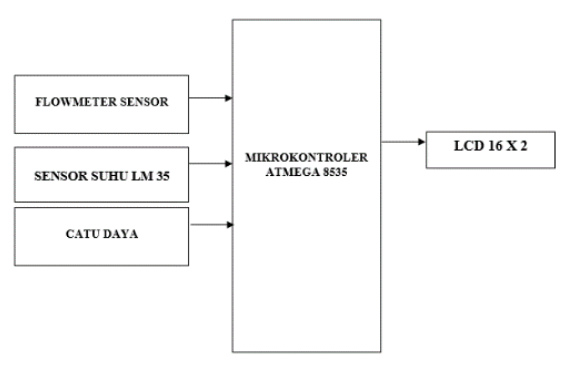

Gambar 1 Blok Diagram

\section{ALAT}

Alat yang digunakan untuk penelitian dan pengujian sebagai berikut:

1. Mikrokontroler ATMega 8535

2. Sensor Aliran Flowmeter

3. Sensor Suhu LM35

4. LCD $6 \times 12$

5. Wadah Air

6. Pompa Air Akuarium Submarine

7. Pipa PVC

8. Software CODEVISION AVR 02.05.3

9. Gelas ukur

10. Stopwatch

11. Termometer

\section{PERANCANGAN}

Proses perancangan alat ini terbagi menjadi dalam 2 langkah antara lain :

\section{Perancangan Software}

Pada perancangan software ini, akan diatur bagaimana kerja dari rangkaian yang akan dibuat dengan cara membuat program menggunakan instruksi - instruksi yang ada pada CodeVision AVR 02.05.3

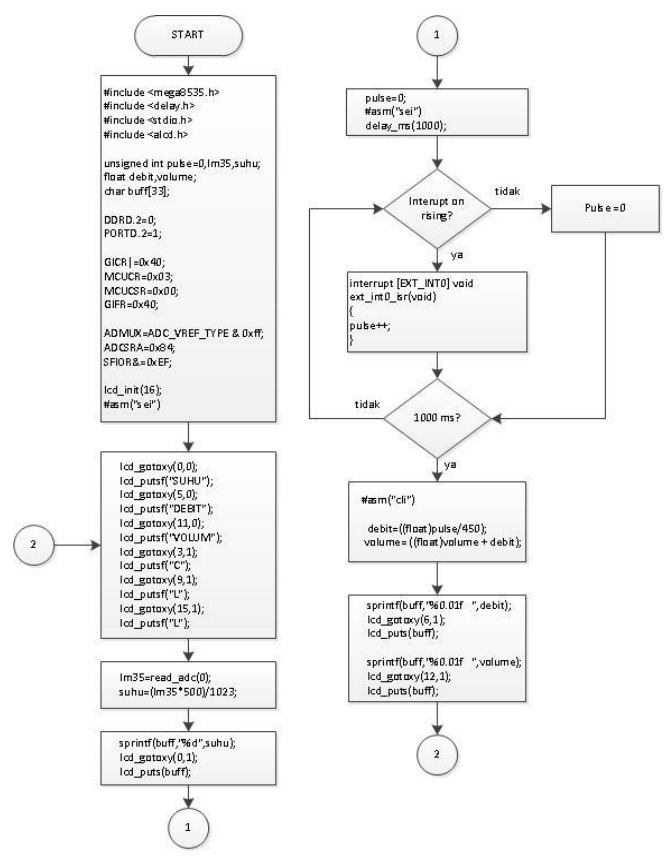

Gambar 2 Listing Program 
2. Perancangan Hardware

Pada perancangan hardware ini terdiri dari 2 bagian yaitu rangkaian elektronik dan wadah air penampung.

Berikut gambar rangkaian perangkat dan rangkaian elektronik.

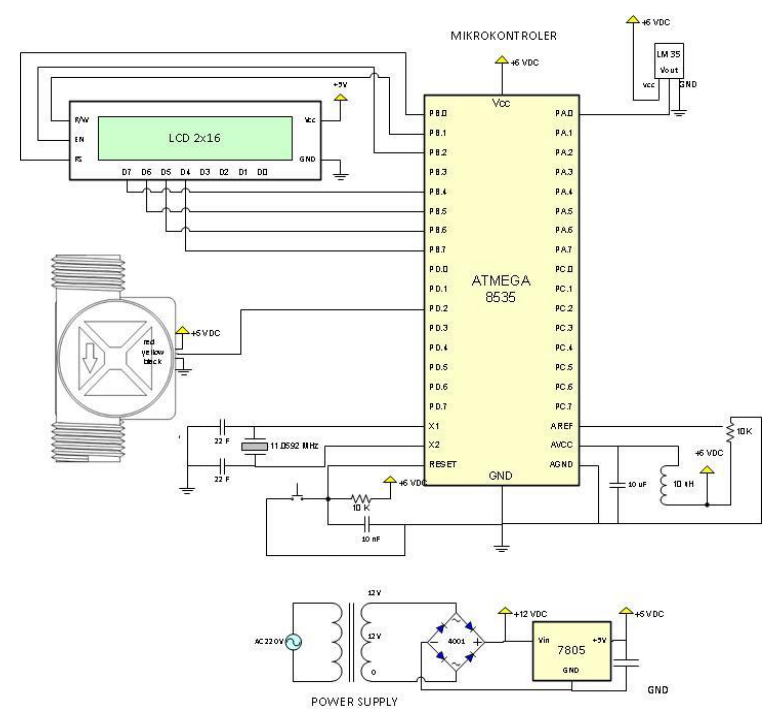

Gambar 3. Rangkaian Perangkat Penelitian

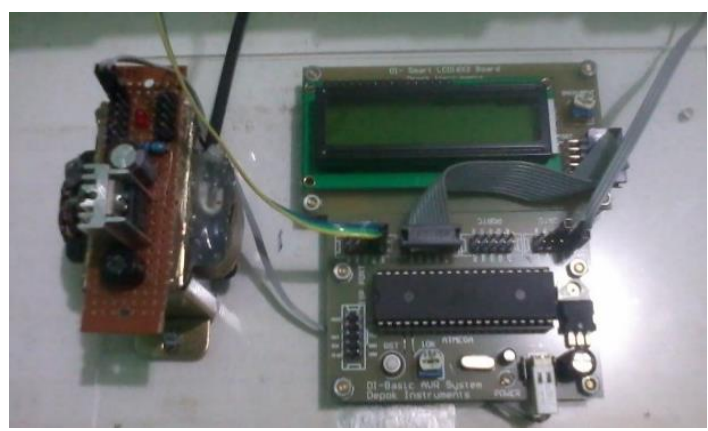

Gambar 4. Rangkaian Elektronik Perangkat Penelitian

Wadah air sebagai penampung terbuat dari akrilik dengan ketebalan $5 \mathrm{~mm}$ dan terdiri dari dua ukuran $\mathrm{p} \times \mathrm{I} \times \mathrm{t}$ yaitu ukuran $30 \mathrm{~cm} \times 30 \times 50 \mathrm{~cm}$ dan $28 \mathrm{~cm} \times 28 \times 48 \mathrm{~cm}$.

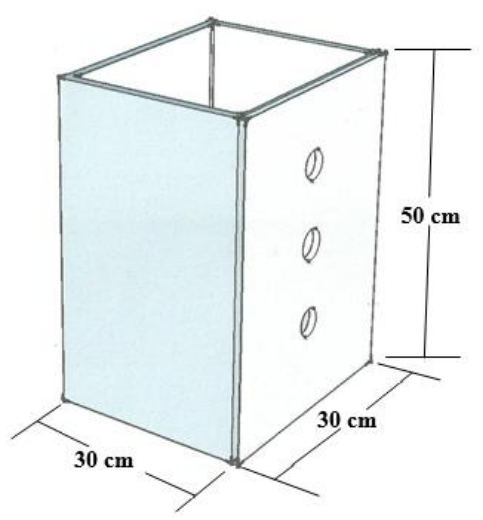

Gambar 5 Wadah Air Ukuran Besar

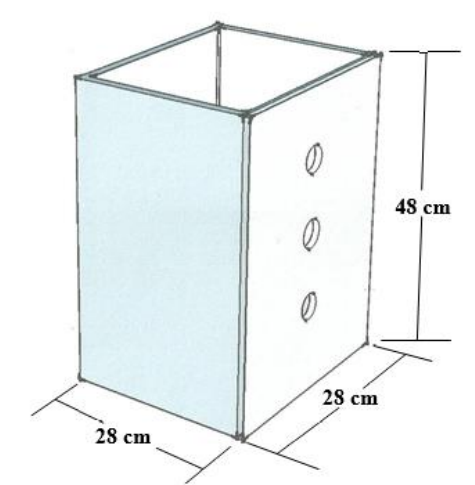

Gambar 6 Wadah Air Ukuran Kecil

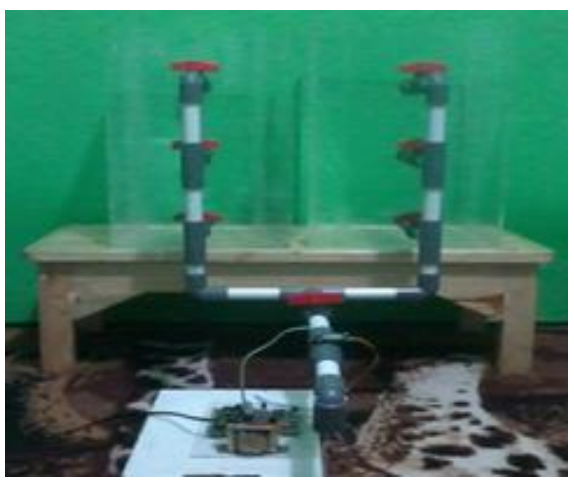

Gambar 7 Perangkat Penelitian

Pada gambar 7 terlihat rangkaian elektronik dan wadah air yang sudah dirangkai dan siap untuk dilakukan pengujian debit dan suhu air. 


\section{ALUR KERJA}

Bentuk alur kerja dari perancangan terdapat pada gambar di bawah ini :

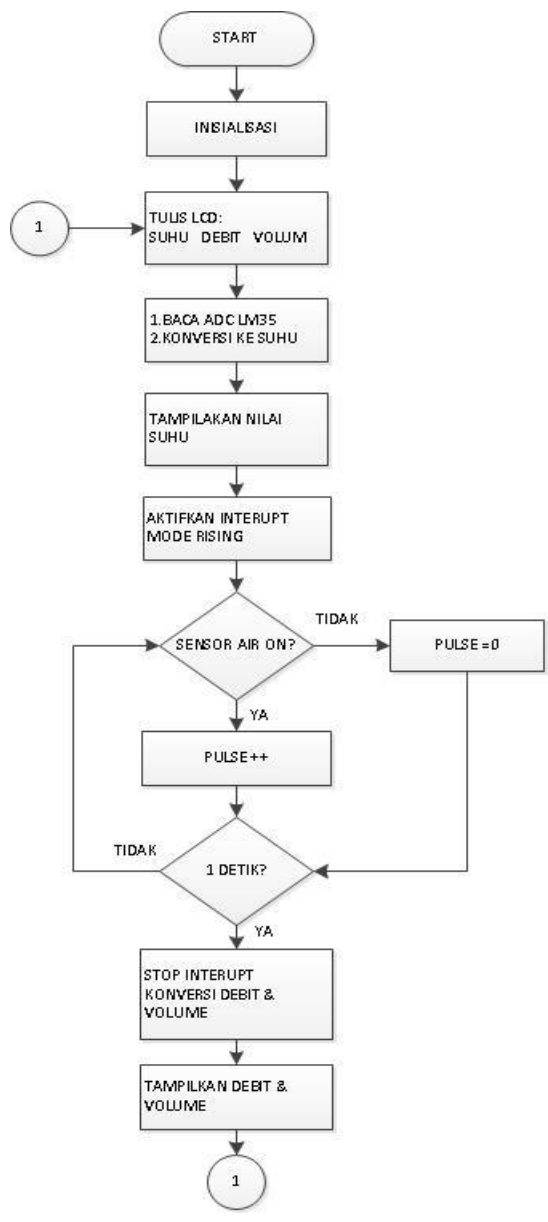

Gambar 8 Alur Kerja

\section{HASIL PENGUJIAN}

Pengujian terhadap alat akan dilakukan dengan pengukuran berupa pencatatan dan pencocokan data waktu, volume, suhu, dan debit air yang mengalir antara data yang muncul pada display LCD dengan data pengukuran fisik sebenarnya.

Pengukuran akan dilakukan pada setiap titik sambungan diantara dua wadah air.

Untuk mendukung proses pencocokan data hasil pengukuran , maka diperlukan beberapa peralatan untuk menguji antara lain :
1. Termometer

2. Gelas ukur

3. Multimeter

4. Stopwatch

Pengujian data hasil pengukuran dilakukan dalam tiga tahap yaitu :

a. Pemeriksaan data suhu dan volume ketika air yang akan diukur dimasukan ke dalam wadah.

b. Pencatatan hasil pengukuran berupa data suhu, volume, dan debit air. Baik yang tampil dalam LCD maupun perhitungan debit dan suhu secara manual menggunakan gelas ukur, stopwatch, dan termometer.

c. Pencocokan data hasil pengukuran secara manual dengan hasil yang tampil pada LCD.

Hasil pengukuran dan pengujian akan ditampilkan dalam bentuk tabel sehingga lebih mudah untuk dilihat dan dianalisis.

Tabel 1 Pencatatan Awal

\begin{tabular}{|c|c|c|}
\hline Besaran & Wadah Air A & Wadah Air B \\
\hline Volume & 45 Liter & 37,6 Liter \\
\hline Suhu & $27^{\circ} \mathrm{C}$ & $27^{\circ} \mathrm{C}$ \\
\hline
\end{tabular}

Tabel 2 Pengukuran Tegangan Listrik

\begin{tabular}{|c|c|c|c|}
\hline Besaran Listrik & Catu Daya & Sensor Suhu LM 35 & Flowmeter \\
\hline \multirow{2}{*}{ Tegangan } & \multirow{2}{*}{12,26 Volt } & $270 \mathrm{mV}$ & Pulsa Tinggi $=4,98$ Volt \\
\cline { 4 - 4 } & & & Pulsa Rendah $=0,23$ Volt \\
\hline
\end{tabular}


Hasil pengukuran tegangan listrik pada sensor suhu LM35 menunjukan 270 $\mathrm{mV}$ yang mana setara dengan $27^{\circ} \mathrm{C}$ pada LCD dan pengukuran pada sensor laju aliran air menunjukan pada pulsa rendah balingbaling Flowmeter tidak berputar ( 0,0 liter/detik) dan pulsa tinggi baling-baling Flowmeter berputar ( 0,4 liter/detik).

Tabel 3 Pengukuran Debit secara manual

\begin{tabular}{|c|c|c|c|}
\hline \multirow{2}{*}{ Besaran } & \multicolumn{3}{|c|}{ Kombinasi Wadah Air Besar dan Kecil } \\
\cline { 2 - 4 } & Katup Bawah & Katup Tengah & Katup Atas \\
\hline Volume & 23 liter & 23 liter & 19 liter \\
\hline Waktu & 230 detik & 115 liter & 63 liter \\
\hline Debit & 0,1 liter/detik & 0,2 liter/detik & 0,3 liter/detik \\
\hline Rata-rata Debit & \multicolumn{3}{|c}{0,159 liter/detik } \\
\hline
\end{tabular}

Tabel 4 Pengukuran Debit Flowmeter

\begin{tabular}{|c|c|c|c|}
\hline \multirow{2}{*}{ Besaran } & \multicolumn{3}{|c|}{ Kombinasi Wadah Air Besar dan Kecil } \\
\cline { 2 - 4 } & Katup Bawah & Katup Tengah & Katup Atas \\
\hline Volume & 23 liter & 23 liter & 19 liter \\
\hline Waktu & 230 detik & 115 liter & 63 liter \\
\hline Debit & 0,1 liter/detik & 0,1 liter/detik & 0,3 liter/detik \\
\hline Rata-rata Debit & \multicolumn{3}{|c}{0,13 liter/detik } \\
\hline
\end{tabular}

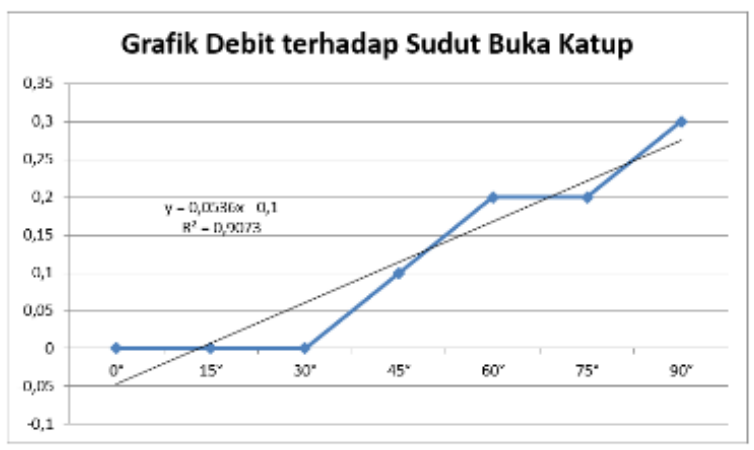

Gambar 9 Grafik Debit terhadap Sudut Buka Katup
Hasil pengukuran debit terhadap sudut buka katup menunjukan grafik yang hampir linier dimana terdapat nilai Persamaan Garis Lurus yaitu $Y=0,0536 X-$ $0,1$ (Gradien $=0,0536$ dan Konstanta $=-0,1)$.

Ketidaklinieran ini disebabkan kurang optimlnya efisiensi Flowmeter dan pompa air. Hal ini terlihat dari hasil pengukuran debit air secara manual dari Flowmeter dan kedua pompa air dimana pada perhitungan secara manual didapat rata-rata debit sebesar 0,159 liter/detik sedangkan pada tampilan LCD terhitung rata-rata debit 0,13 liter/detik. Sehingga terlihat efisiensi Flowmeter sebesar $81,76 \%$.

Sedangkan pada pompa air berdasarkan spesifikasi produsen ditetapkan debit pompa air 6000 liter/jam atau 1,6 liter/detik namun ternyata hanya menghasilkan debit 0,43 liter/detik atau mengalirkan 20 liter air selama 46 detik. Sehingga efisiensi kerja pompa air adalah $26,875 \%$.

\section{Tabel 5 Pengukuran Efisiensi Debit Flowmeter}

\begin{tabular}{|l|l|l|l|l|}
\hline Volume & Waktu & Debit(Flowmeter) & Debit(Manual) & Efisiensi \\
\hline 65 liter & 408 detik & 0,13 liter/ detik & 0,159 liter/ detik & $81,76 \%$ \\
\hline
\end{tabular}

Tabel 6 Pengukuran Efisiensi Debit Pompa Air

\begin{tabular}{|c|c|c|c|c|}
\hline Volume & Waktu & Debit & $\begin{array}{c}\text { Spesifikasi Debit } \\
\text { Pompa Air }\end{array}$ & Efisiensi \\
\hline 20 liter & 46 detik & 0,43 liter/ detik & 1,6 liter/ detik & $26,875 \%$ \\
\hline
\end{tabular}




\section{KESIMPULAN}

Berdasarkan penelitian berupa perancangan dan pembuatan alat dapat disimpulkan hal-hal berikut :

1. Penggunaan sensor laju aliran air dapat diterapkan pada industri pengemasan produk cair. Namun dikhususkan pada produk dengan kapasitas yang menggunakan satuan liter dengan debit 1 liter/menit s.d. 30 liter/menit karena sensor tidak cukup akurat untuk mengukur unit satuan yang lebih kecil.

2. Penggunaan sensor suhu LM35 sudah cukup baik dan sesuai dengan pengukuran manual menggunakan termometer.

3. Penggunaan Mikrokontroler ATMega 8535 sudah cukup baik dan berguna karena banyak fitur yang dapat digunakan.

4. Wadah air yang digunakan sebaiknya yang berbentuk tabung karena wadah air berbentuk balok sangat riskan mengalami kebocoran.

5. Efisiesi pompa air ternyata tidak sesuai dengan efisiensi yang ditetapkan produsen pompa air.

\section{UCAPAN TERIMA KASIH}

Terima kasih penulis haturkan kepada para penulis yang menjadi rujukan dalam penulisan penelitian ini sehingga penelitian ini dapat melengkapi khazanah pengetahuan mengenai penelitian pengukuran debit dan suhu air.

\section{DAFTAR PUSTAKA}

[1] Bagus Hari Sasongko. 2012. Pemrograman Mikrokontroler Dengan Bahasa C. Yogyakarta :Andi Offset.

[2] Erico Darmawan. 2009. Pemrograman Dasar C-JavaC\#. Bandung :Informatika Bandung.
[3] Syahban Rangkuti. 2011. Mikrokontroler Atmel AVR. Bandung :Informatika Bandung.

[4] Wasito. 1995. Vademekum Elektronika. Jakarta : Gramedia Pustaka Utama

[5] Sutrisno.1987. Elektronika dan Penerapannya ( buku 1dan 2 ). Bandung : ITB Bandung.

[6] Albert Paul Malvino. 2004. Prinsip-Prinsip Elektronika. Jakarta :Salemba Empat.

[7] F. Suryatmo. 2005. Teknik Pengukuran Listrik. Jakarta : Bumi Aksara.

[8] Widodo Budiharto dan Sigit Firmansyah. 2010. Elektronika Digital + Mikroprosesor. Yogyakarta : Andi Offset.

[9] Deni Arifianto. 2011. Kamus Komponen Elektronika. Surabaya :Kawan Pustaka.

[10] Thomas Sri Widodo. 2002. Elektronika Dasar. Jakarta :Salemba Empat.

[11] Syam Hardy. 2006. Teknik Dasar-Dasar Elektronika. Jakarta :Rineka Cipta.

[12] Ardi Winoto. 2007. Mikrokontroler AVR ATmega 8/32/16/8535 dan Pemrogramannya dengan Bahasa C pada WinAVR. Bandung : Informatika.

[13] M. Ary Heryanto dan Wisnu Adi P. 2007. Pemrograman C untuk Mikrokontroler ATMega 8535. Yogyakarta : Andi Offset.

[14] Lingga Wardhana. 2006. Belajar Sendiri Mikrokontroler AVR Seri ATMega8535: Simulasi, Hardware, dan Aplikasi. Yogyakarta : Andi Offset.

[15] Romi Budhi Widodo. 2009. Embeddded System Menggunakan Mikrokontroler dan Pemrograman C. 